\title{
MASKING POSTERIOR TOOTH DISCOLORATIONS WITH COLOR MODIFIERS
}

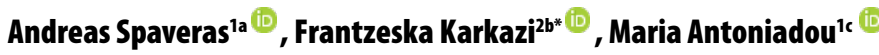 \\ 'Department of Operative Dentistry, Dental School, National and Kapodistrian University of Athens, GR-11527 Athens, Greece \\ ${ }^{2}$ Department of Stomatology and Maxillofacial Surgery, Faculty of Medicine, Comenius University in Bratislava, SK- 81250 Bratislava, Slovakia \\ aDMD, Postgraduate Student \\ ${ }^{\mathrm{M} M D D r}$ \\ DDS, PhD, Assistant Professor
}

\section{ABSTRACT}

DOI: 10.25241/stomaeduj.2018.5(4).art.6

\begin{abstract}
Aim: The present article provides the clinician with a fundamental principle for achieving success with direct application of resinous materials in cases of discolored posterior teeth, mainly due to amalgam corrosion of a previous restoration. The procedure, advantages, and limitations of the technique are discussed.

Summary: A first upper right molar previously filled with amalgam was prepared for a direct composite resin restoration, due to secondary caries. The discolored dentin on the pulpal floor was treated with a white opaquer and a resinous corn color tint also applied with a round painter's brush. Dentin and enamel shade stratification was performed according to the layering technique following the anatomical morphology of the tooth. Finishing was performed with extra-fine diamond burs and aluminum oxide disks. Then a silicon-rubber polishing cups system was used with a $5 \mu \mathrm{m}$ diamond polishing paste in order to achieve high surface gloss.

Key learning points: The preparation of dentin should be kept in minimum in order to follow the principle of minimally invasive dentistry. The application of an opaquer over the discolored dentin should be made in a very thin layer of $0.1 \mathrm{~mm}$. The resinous color modifiers should be applied and layered homogeneously.

Keywords: esthetic conservative direct restoration, posterior tooth, discolored dentin, color modifiers, tints.

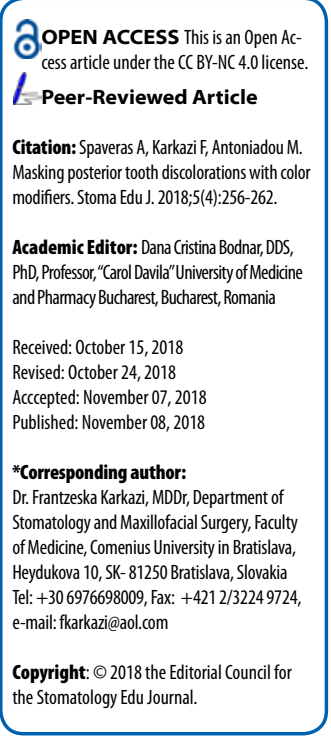

\section{Introduction}

The aesthetic appearance of dentition is of concern to a great percentage of the population. Natural teeth demonstrate translucency, opalescence, and fluorescence, all of which must be replicated by restorative materials in order to achieve clinical success. Therefore, pursuing dental treatment and respecting the natural color of the teeth is of particular cosmetic importance. Frequently, after the removal of a previous amalgam restoration, the exposed dentin commonly appears as a black discoloration, which is attributed to the penetration of corrosion products of amalgam into the dentin. Composites are translucent by nature; even the most opaque shades transmit nearly $60 \%$ of the visible light [1]. As a result, composites require a certain thickness to maintain their intended shade, especially if the underlying substrate is particularly dark. Nevertheless, sometimes even relatively thick composite restorations might not be capable of covering discolored dentin. The dark pulpal wall absorbs a significant part of light that would otherwise reflect towards the occlusal surface, and the restoration, due to that phenomenon, appears a non-vital monochromatic grayish color [2].

Treatment options of direct posterior restorations to minimize the effect of background color include single shade or layering shade technique (dentin /chromatic/achromatic enamel shades), as well as the use of opaquers and tints (color modifiers) willingly. Single-shade restorations are simpler; less technique-sensitive and can reduce chair side time for both the patient and the clinician. However, it is not always easy to achieve a natural tooth structure by using a monochromatic technique, since teeth are multichromatic with color variations. Layering shade technique is required in restorations of high aesthetical demand. The final restoration is usually more natural that single-shade technique, but it is technique sensitive and more time consuming. The proper knowledge of differences in translucency and the required thickness to mask dark background of the applied resin seems to be essential, though little information is available.

Miotti et al. [3] evaluated the ability of three resin composite systems (IPS Empress Direct- Ivoclar Vivadent, Charisma Diamond-Heraeus Kulzer and Filtek Z350 XT-3M, ESPE) to mask a severely discolored background by the application of a layering technique. Three groups presented clinically acceptable color difference values; however, the Filtek Z350 XT system was the only restoration system capable of masking the C4 background. Moreover, Ikeda et al. [4] evaluated the translucency parameter 


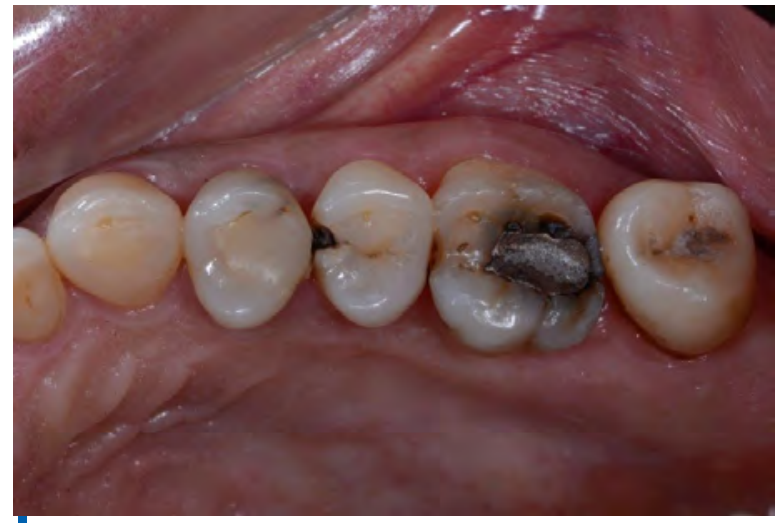

Figure 1. Preoperative occlusal view: insufficient amalgam restoration.

and masking ability of three resin composites with two shades ( $A 3$ and opaque $A 3$ ) and in 1 and $2 \mathrm{~mm}$ thicknesses. They concluded only $2 \mathrm{~mm}$ thickness of the opaque-shade materials could mask the dark background. However, Darabi et al. [5], compared the translucency parameter of five different opaque or dentin A2 shade resin composites Gradia (GC; Tokyo, Japan), Herculite XRV (Kerr, Scafati, Salerno, Italy), Vit-I-escence (Ultradent, South Jordan, UT, USA), Crystalline (Confi-dental, Louisville, KY, USA) and Opallis (FGM, Joinville, Brazil) in different thicknesses and evaluated their masking ability in black backgrounds. They concluded that in relatively thin thicknesses, these opaque/dentin shade composite resins could not mask the black background color.

Color modifiers are used as base liners to counterbalance discolorations or to imitate the natural fissures of the occlusal wall. During the restorative procedure, opaquers block out dark colors, while tints bring the desired color back to the tooth. Opaquers are liquid dimethrycrylate resins (BIS-GMA), which are usually photopolymerised and they contain potent pigments and high opacity percentages in different dentinal shades plus white and pink. They consist of $15 \%$ opaque metal oxides (titanium, zirconium, barium etc.), which increase the opacity and thus the ability to mask dark discolorations [6]. Opaquers are available in a flowable viscocity, in base-catalyst paste form and powder/liquid one. The main benefit of using color modifiers is that there is no need of extended removal of sound dentin, in order to perform a natural looking restoration [7]. When opaquers are used, the protocol presupposes that the discoloration should be covered approximately at $70 \%$. A lower percentage $(<70 \%)$ will result in a grayish restoration, while a higher one $(>70 \%)$ will form an unnatural opaque final appearance. Their application should be in meticulous layers [8]. In highly demanding cases, opaquers and tints could be mixed with composite resins of low viscosity to enhance the opacity of the composites.Tints are resinous materials containing strong pigments, which increase hue and chroma. They transmit light, therefore they add translucency back to restorations after the placement of the opaquer. They are also used in order to reproduce anatomical characteristics

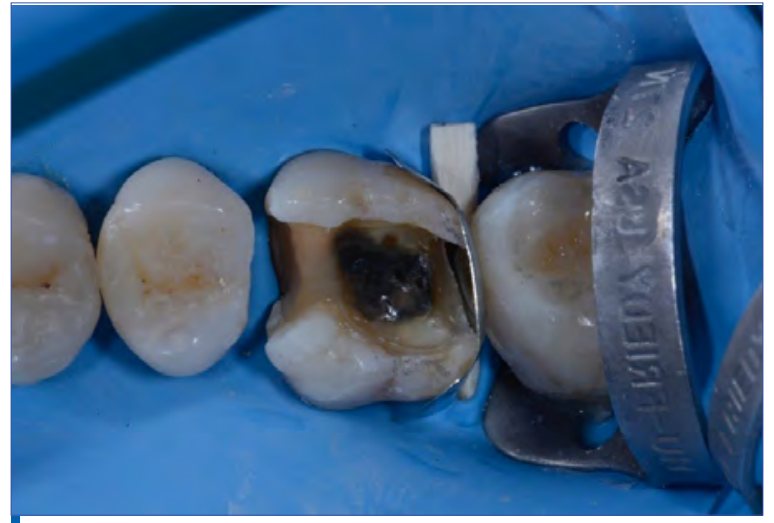

Figure 2. Postoperative situation: examination of the dark discoloration.

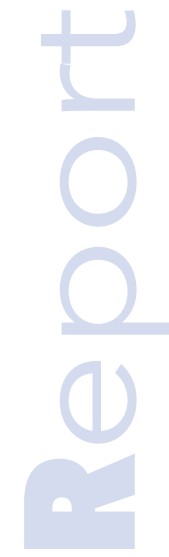

and improve the aesthetics of restorations. Their application should be minimal and under the final composite layer. Shades such as honey, yellow, light/dark brown, ocher and pink are frequently used in the restorations of posterior teeth [9]. It is suggested that clinicians should get familiarized with different color modifiers in laboratory conditions before performing their clinical application. This would enhance their knowledge concerning color modifiers' masking ability and optical characteristics. Moreover, it enables the attainment of individualized and customized composite restorations. The aim of this article is the presentation of a step-to-step direct masking of the discolored dentin of a posterior tooth (\#16) with the aid of color modifiers. Specific clinical tips and potential mistakes made by using such materials are also described thoroughly.

\section{Case Presentation}

A 35-year-old female patient requested the replacement of an insufficient old amalgam restoration of the upper right first molar (\#16), due to secondary caries (Fig. 1).

During the clinical inspection, the tooth did not react sensitively in the cold test and showed no negative reaction to the percussion test. The buccal and palatal walls were measured and were greater than $1.5 \mathrm{~mm}$ in width; therefore a direct restoration could be performed. Tooth shade selection was performed before field isolation to avoid color mismatching, due to the dehydration of dental hard tissues during the procedure. Since, successful composite resin restorations are based on the bond formed between the dental hard tissues and the composite, isolation is an important part in direct restorations. It prevents moisture contamination and ensures increased gingival retraction compared to other techniques. In this clinical case, the upper posterior teeth were isolated with a medium weight rubber dam (Nictone, MDC Dental, Mexico). Two wedges (wooden, orange, Polydentia, Switzerland) were inserted in the mesial and distal interproximal spaces (pre-wedging technique) to overcome the close proximity with the adjacent teeth to prevent removal of sound enamel. The preparation of the cavity was performed mesially, 


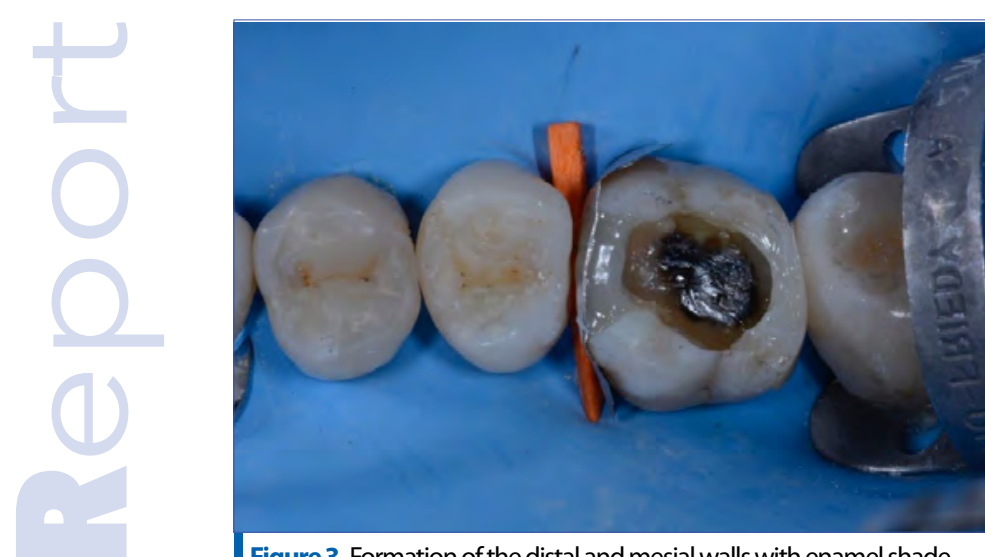

Figure 3. Formation of the distal and mesial walls with enamel shade resin.

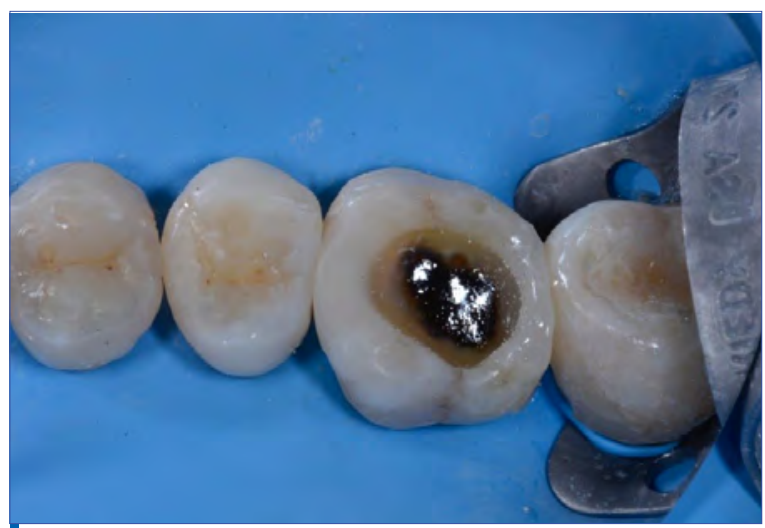

Figure 5. Occlusal view after polymerization of the proximal walls.

occlusally and distally with a medium pear diamond (856, $0.16 \mathrm{~mm}, 10 \mathrm{~mm}$, Comet Gebr., Brasseler) under water-cooling.

After removing the amalgam and while conserving the remaining dental hard tissues, a strong dark discoloration was observed on the pulpal wall (Fig. 2). A $37.5 \%$ phosphoric acid (Gel-Etchant, Kerr Corporation, Orange, CA, USA) was applied to the prepared enamel and dentin for 30 and 15 seconds, respectively. Dental tissues were rinsed and nearly dried with a light air pressure spray ( 2 or 3 seconds). As soon as the etching was performed, sectional matrices (Palodent, Dentsply Sirona) with wedges (wooden, white and orange, Polydentia, Switzerland) were placed on the distal and mesial walls respectively. An adhesive procedure was performed with a three-step etch-and-rinse system (Optibond FL, Kerr Corporation, Orange, CA, USA) according to the manufacturer's instructions of use. Following the adhesion, the proximal walls were formed in order to transform the Class II cavity into a Class I cavity. An enamel shade (Enamel A2, Filtek Supreme Ultimate, 3M ESPE) was used (Fig. 3) for the buildup of the proximal walls. During the polymerization, the sectional matrix was pressed towards the adjacent tooth with a periodontal probe, in order to achieve the appropriate contact point (Fig. 4). Following the interproximal walls construction, the dark discolored pulpal wall was examined carefully, in order to estimate the proper amount of opaquer, which should be used (Fig.

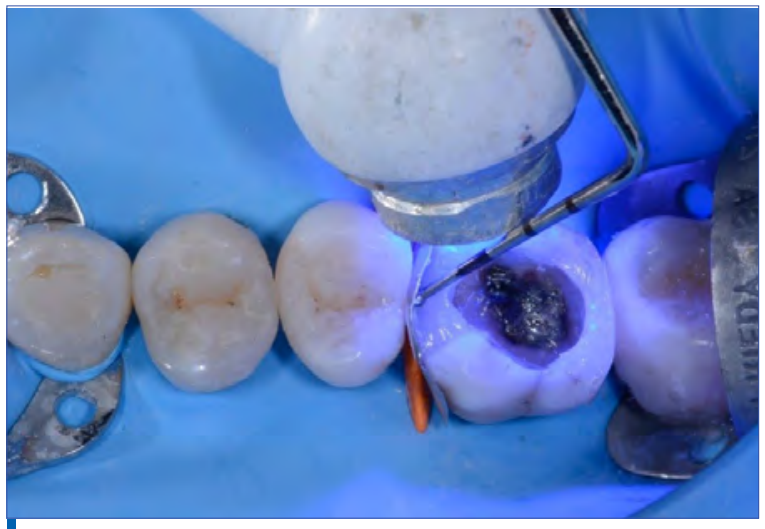

Figure 4. Pressing the sectional matrix towards the neighboring tooth to perform the appropriate contact point..

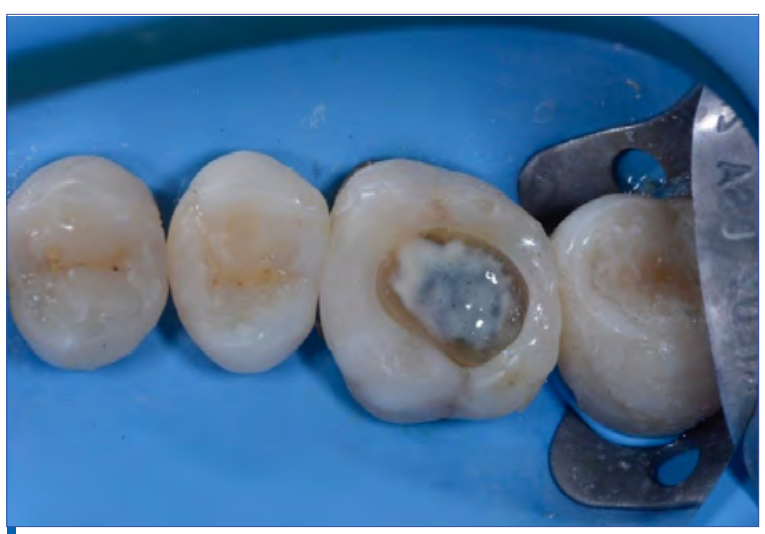

Figure 6. Opaquer placement to the discolored pulpal wall.

5). A small amount of the opaquer (Venus Color White, Heraeus Kulzer GmbH, Hanau, Germany) was applied uniformly in a very thin layer $(0.1 \mathrm{~mm})$ on the discolored pulpal wall with a round painter's brush (Da Vinci, Series 373, Flat No. 2) (Fig. 6). Then, the yellow tint (Corn Inspiro, Edelweiss DR AG, Mercandor, Switzerland) was applied again uniformly in a very thin layer $(0.1 \mathrm{~mm})$ over the previous opaque layer, in order to imitate the yellowish shade of dentin and add some translucency to the restoration (Fig. 7). Each layer was photopolymerized separately with a LED-curing device (TechnoGaz, Parma, Italy) for 20 seconds according to manufacturers' directions of use (Fig. 8). After that, the layering of the dentin composite (Dentin A2, Filtek Supreme Ultimate, $3 \mathrm{M}$ ESPE) was performed, in order to achieve better esthetic appearance of the restoration. The incremental technique was used, to ensure the complete polymerization of all the underlying layers (Fig. 9). A thin layer of the appropriate enamel shade of the same composite system (Enamel A2, Filtek Supreme Ultimate, 3M ESPE), was applied in relation to the morphology of the first upper molar and photopolymerized for $40 \mathrm{~s}$, according to the manufacturers' directions of use (Fig. 10). Finally, the occlusal check was performed with an articulating paper to confirm that the restoration conformed precisely to the patients pre-existing occlusal scheme, in both the intercuspal position and all excursions (Fig. 11). Finishing for accomplishing contouring, shaping and smoothing of the restoration 


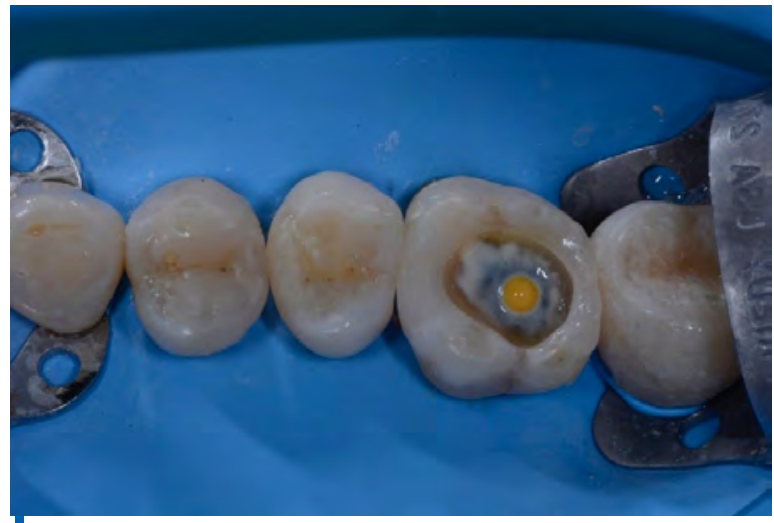

Figure 7. Corn color placement with a small round painter's brush.

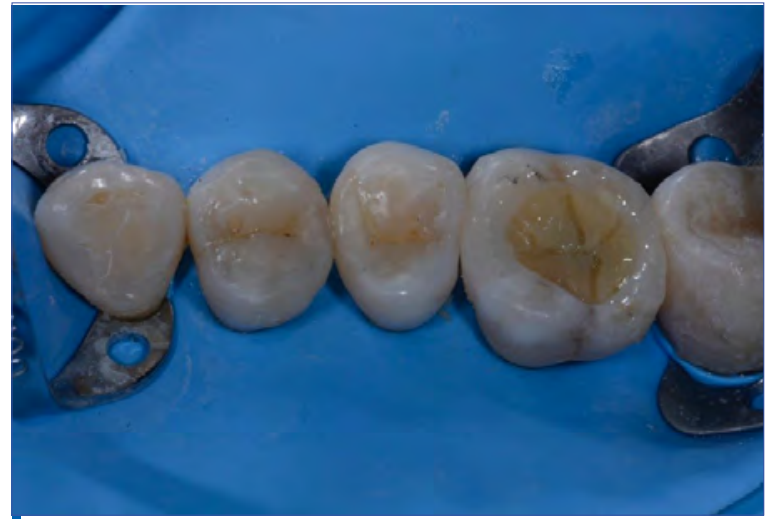

Figure 9. Stratification of the composite resin of dentin shade.

were performed with an extra-fine diamond bur and aluminum oxide disks (Sof-Lex, 3M ESPE AG, Seefeld, Germany), in order to give the proper anatomical morphology and simultaneously to remove all excess at the tooth restoration interfaces. For the polishing, a two-step silicon-rubber polishing cups system (Flexi Cups, Cosmedent, Chicago, IL, USA) and a 5 $\mu \mathrm{m}$ diamond-polishing paste (Diamond Polish Mint, Ultradent Products Inc, South Jordan) were used for 30 seconds, to achieve a higher surface gloss. The final restoration and the neighboring teeth were photo-documented at the end of the restoration (Fig. 12).

\section{Discussion}

Many amalgam restorations have to be replaced due to micro-leakage, recurrent caries, bulk amalgam fracture and sometimes the aesthetic demands of the patient [10]. Amalgam corrosion products penetrate deeply into the dentinal walls and cause dark discolorations [11]. The penetration of black pigments in dentin underneath both high- $\mathrm{Cu}$ and low-Cu amalgams in demineralized specimens are unevenly distributed and observed predominantly in dentin near to pulp horns. Discoloration in the majority of cases is not limited to the outer demineralized dentin but extended beyond this zone. An evenly distributed bluish-green discoloration is frequently observed underneath all high-Cu amalgam specimens independent of demineralization [12]. Therefore, the extension of the cavity preparation to ameliorate the

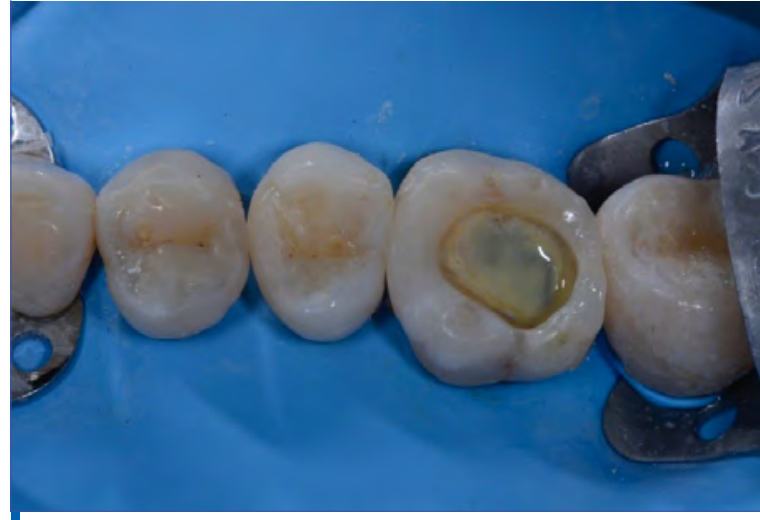

Figure 8. After the polymerization of the tint.

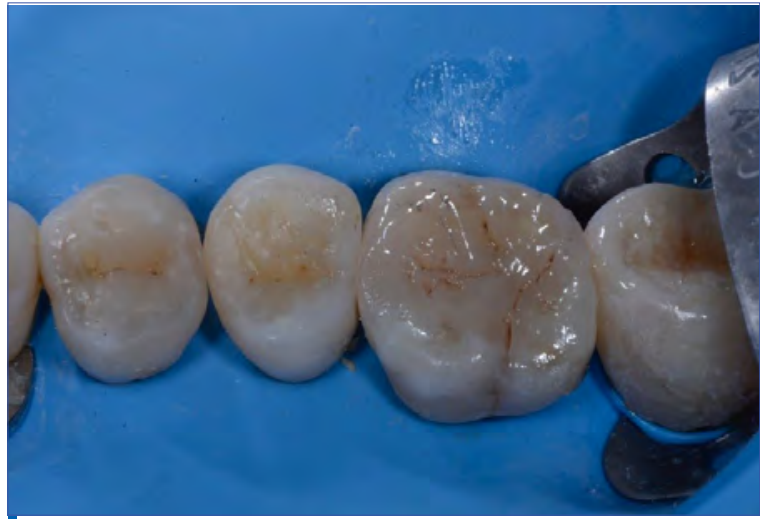

Figure 10. Enamel shade composite placement of the same system.

discoloration might be not beneficial.

Furthermore, a scanning electron microscope (SEM) study of Harnirattisai et al. [13] shows that the majority of the dentinal tubules in cases of discolored dentin were open, but plasma proteins inside the dentinal fluid may reduce the permeability of dentin and interfere with the ability of the resin monomer to infiltrate. As a result, discolored dentin could be considered as a different substrate during clinical procedures, which is able to decrease the bond strength. However, on the basis of an in vitro study, there are no benefits in extending the cavity walls of the preparation, when replacing amalgam restorations [14]. The application of dental liners, bases and cavity varnishes results in reducing microleakage that may cause sensitivity, discolorations and bacterial invasion, due to the fact that these materials are able to seal the dentinal tubules.

Discolorations of posterior teeth should be restored primarily with the least invasive techniques. In more detail, dental bleaching can be used as an alternative or the first treatment step before a direct restoration or to treat a stained arrested caries lesions [15]. Apart from bleaching and the well-established restorative options, a restoration that covers both buccal and cuspal areas can be used, the so called "vonlay". Generally, they are monolithic structure fabricated from lithium disilicate, a vonlay is a hybrid of an onlay with an extended buccal veneer surface for use in bicuspid regions where there is mostly enamel to bond to [16]. Even if extra tooth structure is removed, the problem 


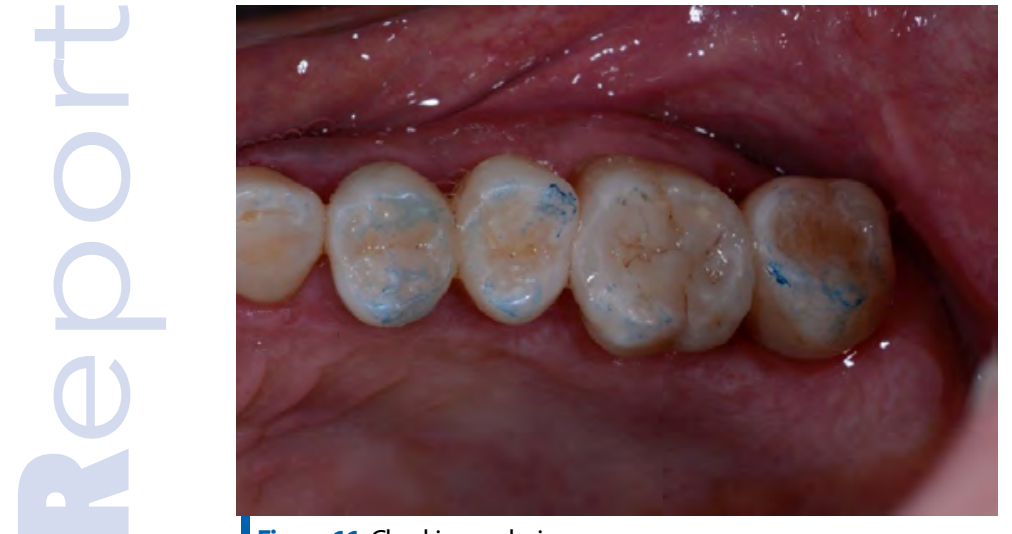

Figure 11. Checking occlusion.

of obtaining an optimal result can be more difficult due to the effect of the underlying resin cement. The tooth shade can also vary somewhat after placing the specific restorations because of a color shift in the polymerized resin cement. On the contrary, the shade of direct composite restorations can be easily modified in order to obtain the optimal result.

It is recommended that general dental practitioners consider adopting minimally invasive techniques in the first instance before moving on to more invasive treatment plans. Indirect restorations require more tooth preparation and more than one appointment to be completed [17-20]. Metal ceramic restorations though they have shown long-term success due to good mechanical properties [21], achieving a natural appearance is more challenging with a metal-ceramic restoration than an all-ceramic restoration due to the fact that metal copings prevent light transmission [22]. Additionally, since porcelain is the main material of choice in the aforementioned treatment plans, there is a high probability of excessive wear of the opposing restoration or the natural tooth, due to the friction between the two [23]. Direct resin composite materials exhibit a promising long-term clinical performance when rehabilitation of posterior teeth is needed [24]. Therefore, they may be used as an equivalent alternative to glass-rich-ceramic inlays regarding mechanical performance [25]. As a result, a direct composite restoration may be the preferable choice, especially if there is adequate tooth structure and the patient is a perfectionist.

In addition, the new generation of composites (nanohybrid composites) has been improved in respect of shade, wear and fracture resistance $[26,27]$. Nanohybrid resin composites are able to imitate ceramic materials in functional and optical aspects $[28,29]$. Even dischromatic posterior areas could be covered with great effectiveness. However, because of their low opacification ability, they sometimes fail to cover very dark discolored pulpal walls of previous amalgam restorations.

In these demanding cases opaquers and tints should be used to counterbalance even the darkest discolorations and simultaneously follow a minimally invasive approach. Therefore, the correct and moderate use of opaquers and tints should be

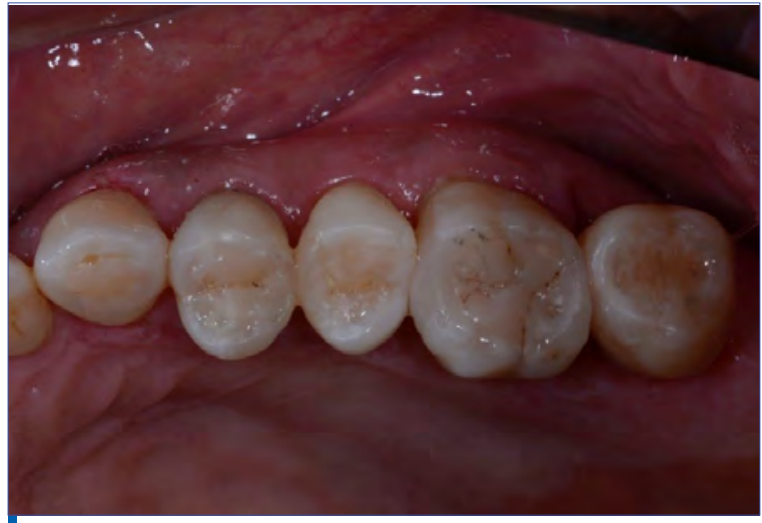

Figure 12. Final occlusal view.

suggested in presenting the "lege artis" of direct posterior restorations.

Clinical tips of how to apply correctly the color modifiers in the posterior restorations will be mentioned below. Color modifiers should be applied homogeneously in very thin layers (0.1-0.5 $\mathrm{mm}$ each) with a small round brush. Moreover, they should be selected carefully. Some of them are highly pigmented, therefore only a single thin layer is needed to obtain an adequate coverage of a discoloration; whereas others may require the application of two or more layers of color modifiers [30]. The clinician has to prepare and preserve an adequate space (minimum $1.5 \mathrm{~mm}$ ); to be filled with resin composite [2,31]. Masking of the opaque layer is also an esthetic necessity. Monochromatic or layering techniques can be either used. However, aesthetics in these situations is usually of high importance, the layering shade technique (enamel-dentin shades) is preferred by many clinicians.

In addition, potential problems regarding the tone of the restorations will be discussed below. Grey restorations may result due to the inefficacy of the opaquer to mask the discoloration or insufficient amount of opaquer applied. A matte restoration may be the result of one of the following: (a) too strong opacification ability of the opaquer, (b) excessive amount of the opaquer and (c) close proximity of the opaquer to the occlusal surface (less than $1.5 \mathrm{~mm}$ ). Spotted restorations are mainly the result of uneven layering of color modifiers [32].

The knowledge and the correct use of color modifiers, as well as, the skills and the aesthetic perception of the dentist are the key factors in establishing a natural result $[33,34]$, particularly when the restoration relates to a single discolored tooth. Therefore, the ability to accurately perceive and differentiate the color characteristics of natural dentition is a major prerequisite for a successful restoration. The aesthetic success of the restoration depends mainly on the correct choice of the shade of the composite and the total opacification ability of the opaquer and the composite materials used. The importance of the specific technique is that even the most difficult and dark pulpal wall discolorations can be covered by simultaneously following the minimally invasive 
approach of cavity preparation.

\section{Conclusions}

Restoring a single posterior discolored posterior tooth with composite resin is a demanding task. Color modifiers should be applied to ameliorate the dark discolorations and simultaneously follow a minimally invasive technique. Their use demands knowledge, experience, training and a feeling of cause and effect. Success in a posterior direct restoration is achieved by applying resinous color modifiers in meticulous layering, use of nanohybrid composite resins of both dentin and enamel shades, finishing and polishing.

\section{Author Contributions}

AS: performed the clinical case. FK: contributed to summarizing the literature and writing the manuscript. MA: contributed to reviewing the manuscript.

\section{Funding}

This research received no external funding.

\section{Conflicts of Interest}

The authors declare no conflict of interest.

\section{References}

1. Naeimi Akbar H, Moharamzadeh K, Wood DJ, Van Noort R. Relationship between color and translucency of multishaded dental composite resins. Int J Dent. 2012;2012:708032. [Full text links] [Free PMC Article] [PubMed] Google Scholar(24) Scopus(7)

2. Dias WR, Pereira PN, Swift EJ Jr. Maximizing esthetic results in posterior restorations using composite opaquers. J Esthet Restor Dent. 2001;13(4):219-227.

[Full text links] [PubMed] Google Scholar(14) Scopus(6)

3. Miotti LL, Santos IS, Nicoloso GF et al. The Use of Resin Composite Layering Technique to Mask Discolored Background: A CIELAB/CIEDE2000 Analysis. Oper Dent 2017:42(2):165-174.

[Full text links] [PubMed] Google Scholar(5) Scopus

4. Ikeda T, Murata Y, Sano H. Translucency of opaque-shade resin composites. Am J Dent. 2004;17(2):127-130.

[PubMed] Google Scholar(73) Scopus(37)

5. Darabi F, Radafshar G, Tavangar M et al. Translucency and masking ability of various composite resins in different thicknesses. J Dent (Shiraz). 2014;15(3):117-122. [Free PMC Article] [PubMed] Google Scholar (5)

6. Lambert D. Simplified solutions to daily anterior aesthetic challenges using a nano-optimized direct restorative material. Dent Today 2005;24(5):94-97.

[PubMed] Google Scholar (6)Scopus

7. Al-Khreisat AS. Evaluating the relative optical translucency of opaquers composite resins. J R Med Serv. 2006;13(2):62-66. Google Scholar(1)

8. Chalkley Y.Treatment of a single stained anterior tooth utilizing visible light-cured opaquer resin and microfil composite resin. lowa Dent J. 1984;70(1):37-39.

Google Scholar (2)

9. Le Sage BP. Aesthetic anterior composite restorations: a guide to direct placement. Dent Clin North Am. 2007;51(2):359-378. [Full text links] [PubMed] Google Scholar(56) Scopus(14)

10. Gawriołek M, Sikorska E, Ferreira LF et al. Color and luminescence stability of selected dental materials in vitro. $J$ Prosthodont. 2012;21(2):112-122.

[Full text links] [PubMed] Google Scholar(29) Scopus(13)

11. Mjör IA, Gordan VV. Failure, repair, refurbishing and longevity of restorations. Oper Dent. 2002;27(5):528-534.
[PubMed] Google Scholar(250) Scopus(142)

12. Scholtanus JD, Van der Hoorn W, Ozcan M et al. Staining of dentin from amalgam corrosion is induced by demineralization. Am J Dent. 2013;26(4):185-190. [PubMed] Google Scholar(5) Scopus(3)

13. Harnirattisai $C$, Senawongse $P$, Tagami J. Microtensile bond strengths of two adhesive resins to discolored dentin after amalgam removal. J Dent Res. 2007;86(3):232-236. [Full text links] [PubMed] Google Scholar(19) Scopus(11)

14. Ghavamnasiri M, Eslami S, Ameri H et al. Effect of amalgam corrosion products in non-discolored dentin on the bond strength of replaced composite resin. J Conserv Dent. 2015;18(1):25-29.

[Full text links] [Free PMC Article] [PubMed] Google Scholar(1) Scopus

15. Al-Angari SS, Hara AT. A conservative approach to esthetically treat stained arrested caries lesions. Quintessence Int. 2016;47(6):499-504.

[Full text links] [PubMed] Google Scholar(2) Scopus(1)

16. McLaren EA, Figueira J, Goldstein RE. Vonlays: a conservative esthetic alternative to full-coverage crowns. Compend Contin Educ Dent. 2015;36(4):286-289.

[PubMed] Google Scholar(7) Scopus(2)

17. Barber AJ, King PA. Management of the single discoloured tooth. Part 2: Restorative options. Dent Update.

2014;41(3):194-196.

[Full text links] [Free PMC Article] [PubMed] Google Scholar(3) Scopus(1)

18. Fradeani M, D'Amelio M, Redemagni M, Corrado M. Five-year follow-up with Procera all-ceramic crowns. Quintessence Int. 2005;36(2):105-113.

PubMed] Google Scholar(153) Scopus(69)

19. Raigrodski AJ, Chiche GJ, Potiket $\mathrm{N}$ et al. The efficacy of posterior three-unit zirconium-oxide-based ceramic fixed partial dental prostheses: a prospective clinical pilot study. $J$ Prosthet Dent. 2006;96(4):237-244.

[Full text links] [PubMed] Google Scholar(612) Scopus(341)

20. Shi JY, Li X, Ni J, Zhu ZY. Clinical Evaluation and Patient Satisfaction of Single Zirconia-Based and High-Noble Alloy Porcelain-Fused-to-Metal Crowns in the Esthetic Area: A Retrospective Cohort Study. J Prosthodont. 2016;25(7):526530.

[Full text links] [PubMed] Google Scholar(11) Scopus(5)

21. Harada K, Raigrodski AJ, Chung KH et al. A comparative evaluation of the translucency of zirconias and lithium disilicate for monolithic restorations. J Prosthet Dent. 2016;116(2):257-263.

[Full text links] [PubMed] Google Scholar(52) Scopus(24)

22. Tabatabaian F, Javadi Sharif M, Massoumi F, Namdari M. The color masking ability of a zirconia ceramic on the substrates with different values J Dent Res Dent Clin Dent Prospects. 2017;11(1):7-13.

[Full text links] [Free PMC Article] [PubMed] Google Scholar(4) Scopus

23. Rashid $\mathrm{H}$. The effect of surface roughness on ceramics used in dentistry: A review of literature. Eur J Dent. 2014;8(4):571 579

[Full text links] [Free PMC Article] [PubMed] Google Scholar(48) Scopus(24

24. Angeletaki F, Gkogkos A, Papazoglou E, Kloukos D. Direct versus indirect inlay/onlay composite restorations in posterior teeth. A systematic review and meta-analysis. $J$ Dent. 2016:53(October):12-21. [Full text links] [PubMed] Google Scholar(33) Scopus(10)

25. Belli R, Geinzer E, Muschweck A, Petschelt A, Lohbauer $U$. Mechanical fatigue degradation of ceramics versus resin composites for dental restorations. Dent Mater. 2014;30(4):424-432.

[Full text links] [PubMed] Google Scholar(120) Scopus(60)

26. Suzuki S, Nagai E, Taira Y, Minesaki Y. In vitro wear of indirect composite restoratives. J Prosthet Dent. 2002;88(4):431-436. [Full text links] [PubMed] Google Scholar(103) Scopus(64)

27. Ku CW, Park SW, Yang HS. Comparison of the fracture strengths of metal-ceramic crowns and three cerome crowns. J Prosth Dent. 2002;88:170-175.

[Full text links] [PubMed] Google Scholar(108) Scopus(42)

28. Fahl N Jr. A polychromatic composite layering approach for solving a complex Class IV/direct veneer/diastema combination: Part II. Pract Proced Aesthet Dent. 2007;19(1):1722.

[PubMed] Google Scholar(74) Scopus(17)

29. Beddis HP, Nixon PJ. Layering composites for ultimate aesthetics in direct restorations. Dent Update. 2012;39(9):630 632, 634-636.

[PubMed] Google Scholar(7) Scopus(1)

30. An JS, Son HH, Qadeer S, Ju SW, Ahn JS. The influence of a continuous increase in thickness of opaque-shade composite resin on masking ability and translucency. Acta Odonto Scand. 2013;71(1):120-129.

[Full text links] [PubMed] Google Scholar(10) Scopus(4) 
31. Milhauser SA, Molnick CP. Clinical application and evaluation of two light-activated color modifiers for composite resin restorations. NY State Dent J. 1983;49(6):397-398. [PubMed] Google Scholar(3) Scopus(1)

32. Felippe LA, Monteiro S Jr, Baratieri LN et al. Using opaquers under direct composite resin veneers: an illustrated review of the technique. J Esthet Restor Dent. 2003;15(6):327-336; discussion 337.
[Full text links] [PubMed] Google Scholar(24) Scopus(7) Bichacho N. Direct composite resin restorations of the anterior single tooth: clinical implications and practical applications. Compend Contin Educ Dent. 1996;17(8):796-862. [PubMed] Google Scholar(25) Scopus (13)

34. Dietschi D. Layering concepts in anterior composite restorations. J Adhes Dent. 2001;3(1):71-80. [PubMed] Google Scholar(177) Scopus(56)

\section{Andreas SPAVERAS}

DMD, Postgraduate Student Department of Operative Dentistry Dental School, National and Kapodistrian University of Athens, GR-11527 Athens, Greece

Dr. Andreas Spaveras received his degree in dentistry (DMD) in 2013 from the Semmelweis University of Budapest, Hungary. Currently, he is finishing his postgraduate studies (MSc) at the Restorative Dentistry Department, Dental School of the National and Kapodistrian University of Athens, Greece. He has published several scientific articles in the field of restorative dentistry.

\section{Questions}

\section{Color Modifiers promote:}

$\square$ a. Non-invasive procedures;

Db. Minimally invasive indirect restorations;

Uc. Minimally invasive direct restorations;

ad. Invasive restorations.

\section{Color modifiers should be applied:}

$\square$ a. In very thin layers (0.1-0.5 mm each);

ab. In thin layers (0.5-0.7 $\mathrm{mm}$ each);

Uc. In moderate layers (0.7-1.2 mm each);

$\square d$. In thick layers (1.2-1.5 mm each).

\section{Opaquers and Tints should be applied homogeneously with:}

口a. A probe;

ab. A micro-brush;

ac. A small round painter's brush;

$\square$ d. A flat painter's brush.

\section{The clinician has to prepare and preserve:}

Da. A minimum $1.0 \mathrm{~mm}$ space to be filled with resin composite; Db. A minimum $1.5 \mathrm{~mm}$ space to be filled with resin composite; dc. A minimum $2.0 \mathrm{~mm}$ space to be filled with resin composite; Dd. A minimum $3 \mathrm{~mm}$ space to be filled with resin composite. 